\title{
A 'systems' approach to suicide prevention: radical change or doing the same
} things better?

\section{Scott J Fitzpatricka,c and Claire Hooker ${ }^{b}$}

a Centre for Rural and Remote Mental Health, University of Newcastle, NSW, Australia

${ }^{b}$ Centre for Values, Ethics and the Law in Medicine, University of Sydney, NSW, Australia

cCorresponding author: scott.fitzpatrick@newcastle.edu.au

\section{Article history}

Publication date: April 2017

Fitzpatrick SJ, Hooker C. A 'systems' approach to suicide prevention: radical change or doing the same things better? Public Health Res Pract. 2017;27(2):e2721713. doi: http://dx.doi. org/10.17061/phrp2721713

\section{Key points}

- Development of the Suicide Prevention Framework for NSW draws on international evidence for a multicomponent 'systems' approach

- The proposed Framework will ensure that interventions are integrated and will maximise available resources

- To improve long-term success, the complexity of suicide and the systems that surround it need to be considered

- A response that includes discussion and action on the social and political determinants of suicide is crucial

\section{Abstract}

Suicide is a significant public health concern. Continued high suicide rates, coupled with emerging international evidence, have led to the development of a 'systems' approach to suicide prevention, which is now being trialled as part of a proposed Suicide Prevention Framework for NSW (New South Wales, Australia).

The Framework replicates successful international approaches. It is organised around nine components, ranging from individual to population-level approaches, to improve coordination and integration of existing services.

If implemented fully, the Framework may lead to a significant reduction in suicide. However, to ensure its long-term success, we must attend to underlying structures within the system and their interrelationships. Such an approach will also ensure that policy makers and local suicide prevention action groups, particularly in rural areas, are able to respond to local challenges and incorporate multiple perspectives into their practice, including evidence for the broader social determinants of suicide.

\section{Introduction}

Despite concerted efforts, death rates from suicide in Australia have not decreased appreciably over recent decades. ${ }^{1}$ In 2016, the New South Wales (NSW) and Victorian governments committed to trialling a 'systems' approach to suicide prevention to address this important issue. ${ }^{2}$ The new approach is commendable and draws on international evidence that indicates that integrated, multifaceted and multilevel systems approaches are associated with reductions in suicide rates. ${ }^{3}$ This is because of potential synergies between individual components that, alone, have been shown to have only limited efficacy. ${ }^{4,5}$ Although differences exist in the number and selection of core components in similar multicomponent strategies, a number of bestpractice activities have evolved to guide policy makers in the development of national suicide prevention strategies. ${ }^{3}$ 
We recognise the opportunities this new approach offers. In Australia, silos in suicide prevention mean that there has been little vision, and no means to show how national and state governments, community organisations and consumer groups can work together. ${ }^{6}$ The systems approach offers this vision and provides for muchneeded coordination and integration of existing national and state-level services. This approach is expected to minimise duplication, ensure that a range of services are available for people at risk of suicide, and create opportunities for local communities to advocate for, or develop, new services or programs to fill gaps in local service provision. ${ }^{4}$ The systems approach is deliberately outcomes focused. Although broader issues, such as social determinants of suicide, are considered important, the aim is to eschew these in favour of immediate implementation of already proven actions, and thus to have a swift, positive impact on national suicide rates. ${ }^{4}$

The idea of getting something done is compelling, and we agree that the systems approach will have a good chance of achieving a significant reduction in suicide rates. We are also aware that devils will lie in the details of implementation. Grasping these devils is likely to lead us back inexorably to the broader social determinants of suicide and the need to attend to the underlying structures within the system. ${ }^{7}$

\section{The Framework in practice in rural communities}

Although rates of reported mental disorders in rural communities are similar to those in urban areas, suicide rates among young rural men have been increasing, suggesting that socio-economic determinants are likely to contribute as much as, if not more than, individual factors. ${ }^{8,9}$ Under the proposed Suicide Prevention Framework for NSW (the Framework), these communities would conduct a suicide audit of existing services and programs, and use it to develop a suicide prevention action plan, involving implementation of any number of nine components the Framework identified as being of demonstrated efficacy. However, the Framework recognises that 1) not all local areas will have all nine components in place or available, and, indeed, depending on the size of the area and available resources, some local areas may have only one or two components; 2) it is impossible to say how many of these components are required to maximise the preventive effect; and 3) not all components will be equally effective, because some operate further upstream than others. ${ }^{4}$ And herein lies a potential - we would argue, a probable - devil.

It is not hard to imagine how easily the hardworking members of a multiagency suicide prevention group in a small rural town could become stymied and burnt out if a policy regime of budget cuts to multiple services removes the capacity to put in place more than two of the nine components, while simultaneously creating the conditions for rising suicide rates. At some point, not talking about this while getting on with whatever is within practical reach will be less and less satisfying.

To be functional for rural and regional communities, the Framework would require 1) the ability for a proposed robust evaluation strategy to identify where (and, ideally, why) the absence of any of the nine components makes a significant difference to the functioning of the whole system; 2) resources to supply the deficiency; and 3) capacity to shift among the nine components as unpredicted change within the system occurs. The latter includes the ability to critique or jettison not only any of the nine components but the very definition of what constitutes 'the system': what kinds of 'evidence' will count and why, and the ways in which suicide is conceptualised. ${ }^{10}$ As suggested above, sometimes this may mean bringing those very elements that the Framework eschews - social determinants of suicide and an expanded concept of what a systems approach to suicide could mean - back into view.

\section{Evaluating the Framework}

At present, the Framework predominantly focuses on coordination and streamlining of existing individual system components. Change efforts focus on establishing centralised and local governance arrangements to manage resourcing, implementation, monitoring and evaluation of the Framework. In other words, it is mostly concerned with doing the same things better by making incremental or first-order change. ${ }^{7}$

The question will be how to shift from the pursuit of the 'quick wins' the Framework understandably prioritises to second-order or radical change. In contrast to first-order change, second-order change takes as its starting point the way a problem is perceived. Crucially, it accommodates different, competing perspectives of a problem to bring about shifts in understanding, including what needs to be done to solve the problem. $^{7}$

It is easy for the role of inappropriate service models and norms of care to fall out of sight in practice. To limit this, evaluation of the process must track how implementation of the Framework is nested within other systems that affect, and are affected by, system change measures. ${ }^{7}$ Recent World Mental Health Survey data have shown that many individuals prefer to manage suicidal crises outside healthcare settings. ${ }^{11}$ This is troubling, especially when low perceived need is because of ineffective treatment, dissatisfaction with mainstream services, or previous contact with uncaring practitioners. ${ }^{12}$ So an evidence based approach is urgently needed ${ }^{13}$, with evidence about what qualities of care make components of a suicide prevention system more or less successful, not just what combination of components might work. 
Recent systems-change literature points to the significance of attending to underlying normative elements of a system. Successful implementation of the Framework will likely depend on such slippery but significant things as the beliefs, values and tacit assumptions that drive the behaviour of stakeholders both within the networks of service providers across the nine components and in the context of their continued operation. Particular attention to these characteristics across systems levels and stakeholders will address the complexity of suicide and its prevention, and identify areas of support for, or resistance to, change. ${ }^{7}$ Young people in rural areas talk about unemployment, poor economies and local norms. ${ }^{14}$ Farmers talk about unjust social and economic relations between farmers, corporations and the state. ${ }^{15}$ Indigenous communities talk about forced relocation, intergenerational trauma and a diminished sense of cultural identity. ${ }^{16}$ Our own values, if nothing else, lead us to want to keep such things clearly in view.

\section{Conclusion}

We appreciate the importance of quick wins, of making the most of the resources we have, and of the manifold opportunities the proposed Framework offers to enable those who work in suicide prevention to finally make the connections, avoid the duplications, tailor the components and engage the communities as they have often wished to do. We are confident they will see some reward for their efforts. We hope to support the Framework by continuing to suggest ways in which the complexity of suicide and the systems that surround it can be considered.

\section{Competing interests}

None declared

\section{Author contributions}

SF led the writing and editing of first and subsequent drafts, and helped rewrite the article in response to peer reviews. $\mathrm{CH}$ contributed feedback on drafts of the article, prepared a substantial proportion of subsequent drafts and helped rewrite the article in response to peer reviews.

\section{References}

1. Hunter Institute of Mental Health. Suicide figures (ABS 2016). Newcastle: Hunter Institute of Mental Health; 2016 [cited 2016 Oct 20]. Available from: www.mindframemedia.info/_data/assets/pdf_file/0018/12834/Suicidefigures-ABS-2016_final3.pdf
2. LifeSpan. Integrated suicide prevention. Sydney: LifeSpan; 2016. Victoria supporting a systems approach to suicide; 2016 Aug 2 [cited 2016 Oct 20]; [about 1 screen]. Available from: www.lifespan.org.au/victoriasupporting-a-systems-approach-to-suicide-prevention

3 World Health Organization. Preventing suicide: a global imperative. Geneva: World Health Organization; 2014 [cited 2016 Oct 20]. Available from: www.who.int/mental_ health/suicide-prevention/world_report_2014/en

4. NHMRC Centre for Research Excellence in Suicide Prevention (CRESP), Black Dog Institute, Mental Health Commission of New South Wales. Proposed suicide prevention framework for NSW 2015. Sydney: CRESP; 2015 [cited 2016 Oct 20]. Available from: nswmentalhealthcommission.com.au/sites/default/ files/Subfolder/PROPOSED SUICIDE PREVENTION FRAMEWORK FOR NSW 2015-2020 4 Aug 2015.pdf

5. van der Feltz-Cornelis CM, Sarchiapone M, Postuvan V, Volker D, Roskar S, Grum AT, et al. Best practice elements of multilevel suicide prevention strategies. Crisis. 2011;32(6):319-33.

6. Senate Standing Committee on Community Affairs. The hidden toll: suicide in Australia. Canberra: Commonwealth of Australia; 2010 [cited 2016 May 6]. Available from: www.aph.gov.au/ /media/ wopapub/senate/committee/clac_ctte/completed_ inquiries/2008_10/suicide/report/report_pdf.ashx

7. Foster-Fishman PG, Nowell B, Yang H. Putting the system back into systems change: a framework for understanding and changing organizational and community systems. Am J Community Psychol. 2007;39(3-4):197-215.

8. Page A, Morrell S, Taylor R, Dudley M, Carter G. Further increases in rural suicide in young Australian adults: secular trends, 1979-2003. Soc Sci Med. 2007;65(3):442-53.

9. Knox KL, Conwell $\mathrm{Y}$, Caine ED. If suicide is a public health problem, what are we doing to prevent it? Am J Public Health. 2004;94(1):37-45.

10. Hawe P. Lessons from complex interventions to improve health. Annu Rev Public Health. 2015;36:307-23.

11. Bruffaerts R, Demyttenaere K, Hwang I, Chiu WT, Sampson N, Kessler RC, et al. Treatment of suicidal people around the world. Br J Psychiatry. 2011:199(1):64-70.

12. Pitman A, Osborn DPJ. Cross-cultural attitudes to help-seeking among individuals who are suicidal: new perspective for policy-makers. Br J Psychiatry. 2011;199(1):8-10.

13. National Action Alliance for Suicide Prevention Research Prioritisation Task Force. A prioritized research agenda for suicide prevention: an action plan to save lives. Rockville MD: National Action Alliance for Suicide Prevention; 2014 [cited 2016 Oct 20]. Available from: actionallianceforsuicideprevention.org/sites/ actionallianceforsuicideprevention.org/files/Agenda.pdf 
14. Bourke L. Toward understanding youth suicide in an Australian rural community. Soc Sci Med. 2003;57:2355-65.

15. Bryant L, Garnham B. Economies, ethics and emotions: farmer distress within the moral economy of agribusiness. J Rural Studies. 2014;34:304-312.
16. Wexler L. Looking across three generations of Alaska Natives to explore how culture fosters indigenous resilience. Transcult Psychiatry. 2014;51(1):73-92.

\section{Copyright: (c)(2)}

(C) 2017 Fitzpatrick and Hooker. This article is licensed under the Creative Commons Attribution-NonCommercial-ShareAlike 4.0 International Licence, which allows others to redistribute, adapt and share this work non-commercially provided they attribute the work and any adapted version of it is distributed under the same Creative Commons licence terms. See: www.creativecommons.org/licenses/by-nc-sa/4.0/ 